\title{
Pengaruh Model Pembelajaran Process Oriented Guided Inquiry Learning Berbantuan Media Mind Mapping terhadap Kompetensi Pengetahuan IPA
}

\author{
Era Evangelisa1 ${ }^{*}$, I G A Agung Sri Asri², I Wayan Sujana3 \\ 123 Program Studi Pendidikan Guru Sekolah Dasar, FIP, Universitas Pendidikan Ganesha, Singaraja, \\ Indonesia
}

\begin{abstract}
Abstrak
Penelitian ini bertujuan untuk mengetahui pengaruh yang signifikan model pembelajaran Process Oriented Guided Inquiry Learning berbantuan Mind Mapping terhadap kompetensi pengetahuan IPA siswa SD. Rancangan penelitian yang digunakan Quasi Experiment atau eksperimen semu. Bentuk design yang di gunakan adalah Non Equivalent Control Group Design. Populasi penelitian ini yaitu seluruh siswa kelas V SD yang terdiri dari 456 siswa. Sampel ditentukan dengan teknik cluster random sampling. Kelas VA SD Negeri 17 dauh Puri sebanyak 40 orang siswa sebagai kelompok eksperimen dan kelas V SD Negeri 4 Dauh Puri sebanyak 35 orang siswa terpilih sebagai kelompok kontrol. Setelah semua populasi dinyatakan setara melalui uji beda mean (t-test), maka pengambilan sampel dengan cara pengundian secara acak bisa dilakukan. Dalam proses pengumpulan data, pemilihan metode tes digunakan sebagai instrument yang berbentuk tes pilihan ganda dengan jumlah soal valid sebanyak 40 butir. Uji-t digunakan dalam analisis data penelitian ini dengan teknik analisis inferensial. Perolehan yang didapat melalui uji beda mean (t-test) yakni thitung $=8.08$. Harga tersebut kemudian dibandingkan dengan harga tabel dengan $\mathrm{dk}=40+35-2=73$ dan taraf signifikansi 5\% sehingga diperoleh harga tabel $=1,99$, karena thitung $>$ ttabel $(8.08>1,99)$ maka Ho ditolak. Hal ini menunjukkan bahwa terdapat pengaruh model pembelajaran Process Oriented Guided Inquiry Learning berbantuan media Mind Mapping terhadap kompetensi pengetahuan IPA siswa kelas V SD.
\end{abstract}

\begin{abstract}
This research was aimed to know a significant difference of science knowledge competencies between groups of students that was learned by Process Oriented Guided Inquiry learning model assisted with Mind Mapping and groups of students that was learned by conventional learning in grade V elementary school in Gugus Kapten Japa district for Academic Year 2019/2020. The research design used was quasi-experimental. The design form used is Non Equivalent Control Group Design. All grade V students at Gugus Captain Japa Cluster Elementary School consisted of 456 people being the population. The whole grade VA of SD Negeri 17 Dauh Puri amounted to 40 students and grade V of SD Negeri 4 Dauh Puri amounted to 35 students were selected as samples. After all populations are declared equal by t-test, the random sampling can be done. In the data collection process, the selection of test methods is used as an instrument in the form of multiple choice tests with 40 valid items. T-test is used in the analysis of research data with inferential analysis techniques. Obtained by mean difference test ( $\mathrm{t}$-test), $\mathrm{t}_{\text {count }}=8.08$. The price is then compared to the table price with $\mathrm{dk}=40+35-2=73$ and a significance level of $5 \%$ so that the price ttable $=1.99$ is obtained, because $t_{\text {count }}>t_{\text {table }}(8.08>1.99)$ then Ho is rejected. This means that there is an influence of learned by Process Oriented Guided Inquiry learning model assisted with Mind Mapping and groups of students that was learned by conventional learning in grade V elementary school in Gugus Kapten Japa.
\end{abstract}

\footnotetext{
* Corresponding author. 


\section{PENDAHULUAN}

Dimasa sekarang kemajuan suatu bangsa dapat dilihat dari kemampuan sumber daya manusia yang dimiliki suatu bangsa dalam menguasai ilmu pengetahuan dan teknologi. Maka dari itu untuk memajukan suatu bangsa, salah satu cara untuk mewujudkannya dengan memperhatikan kondisi pendidikannya. Dalam mencapai kualitas yang baik didalam pendidikan, maka diperlukan kurikulum sebagai komponen acuan pendidikan. Pembelajaran di sekolah dasar kini sudah mulai menerapkan kurikulum 2013 yang dimana yang telah terintergrasi atau terpadu sebagai suatu sistem pendekatan pembelajaran yang melibatkan beberapa disiplin ilmu. Pengembangan kurikulum 2013 merupakan kelanjutan kurikulum berbasis kompetensi. Kompetensi merupakan suatu materi pembelajaran atau kemampuan yang harus dicapai oleh siswa untuk disetiap mata pembelajarannya di masing - masing satuan pendidikan yang berpedoman pada kompetensi inti. Ilmu Pengetahuan Alam (IPA) merupakan salah satu muatan materi pelajaran yang termuat didalam kurikulum 2013. IPA didalam kurikulum 2013 merupakan bagian dari mata pelajaran yang sangat penting dalam mengembangkan kemampuan, sikap dan ketreampialan ilmiah pada siswa.

Berdasarkan hasil wawancara dan observasi, pada tanggal 22-27 November 2019 diketahui bahwa kini khususnya di SD Negeri Gugus Kapten Japa sudah menerapkan kurikulum 2013. namun demikian walaupun telah menggunakan kurikulum 2013 dengan pendekatan saintifik, tetapi masih banyak siswa yang kurang aktif dan kurang semangat mengikuti pembelajaran, sehingga materi yang diberikan tidak bisa di terima maksimal. Berdasarkan informasi yang diterima, dalam proses pembelajaran siswa cenderung menghafal materi yang disampaikan sehingga siswa lebih banyak mengingat informasi tanpa dituntut memahami materi yang diingatnya tersebut. Selain itu, masih saja banyak siswa yang kurang aktif dalam mengikuti proses pembelajaran sehingga materi yang diberikan tidak bisa diterima maksimal oleh siswa. Maka, perlu di kembangkannya suatu model pembelajaran yang dapat melibatkan siswa untuk lebih aktif, lebih kreatif, inovatif dan menyenangkan sehingga siswa lebih berfikir secara kritis.

Pada penelitian ini, dicoba suatu model pembelajaran yang menekankan kepada proses. Melalui penemuan konsep secara terbimbing siswa akan dapat memahami konsep yang dipelajari secara lebih mendalam. Salah satu model pembelajaran yang akan digunakan adalah model pembelajaran Process Oriented Guided Inquiry Learning (POGIL). Menurut Hanson (2006:3) model pembelajaran POGIL merupakan pembelajaran aktif dimana pembelajaran dalam kelompok dan inkuiri terbimbing. Model pembelajaran POGIL ini bisa memancing keaktifan siswa dan kemampuan berpikir siswa dalam pembelajaran, belajar bekerjasama dalam tim belajar untuk memahami konsep, dapat menarik kesimpulan dari analisis data, memecahkan suatu masalah dan meningkatnya komunikasi siswa dengan guru yang berperan sebagai fasilitator. Selain menggunakan model pembelajaran POGIL, guru juga memerlukan media pembelajaran yang dapat membantu pemahaman siswa dalam menyerap materi pelajaran. Setelah melakukan pembelajaran POGIL siswa akan memperoleh konsep-konsep dalam materi pembelajaran.

Mind Mapping merupakan salah satu cara mengorganisasikan konsep-konsep yang telah dipelajarioleh siswa. Mind Mapping merupakan suatu media yang dapat mengorganisasikan sebuah informasi ke dalam bentuk gambar, simbol, atau warna secara kreatif dan efektif dengan tujuan untuk memudahkan pemahaman si penerima informasi dan mengingatnya lebih lama (Buzan, 2007). Mind Mapping adalah cara untuk mengasimilasikan konsep-konsep yang telah dipelajari oleh siswa. Pada pembelajaran POGIL, Mind Mapping akan digunakan di akhir pembelajaran untuk mereview apa yang telah diketahui siswa. Kegiatan ini dapat membantu siswa menerima pengetahuan yang telah didapatnya menjadi lebih tersusu atau terstruktur. Dengan menggunakan Model pembelajaran POGIL bebantuan media Mind Mapping diharapkan pembelajaran akan menjadi lebih bermakna. Hal ini didukung dengan hasil penelitian yang dimana telah dilakukan oleh Ni Putu Yuliani tentang "Pengaruh Model Pembelajaran Process Oriented Guided Inquiry Learning Berbantuan Peta Pikiran Terhadap Hasil Belajar IPA Siswa Kelas V SD" (2017). Berdasarkan hasil perhitungan uji-t menunjukan bahwa terdapat perbedaan yang signifikan antara kelompok siswa yang dibelajarkan melalui pengaruh model pembelajaran Process Oriented Guided Inquiry Learning berbantuan Peta Pikiran dengan kelompok siswa yang tidak dibelajarkan dengan pengaruh Model Pembelajaran Process Oriented Guided Inquiry Learning Berbantuan Peta Pikiran. Yudiari, dkk (2015) tentang "Pengaruh Model Pembelajaran SAVI Berbantuan Media Mind Mapping Terhadap Hasil Belajar IPA Siswa Kelas V SD di gugus II Kecamatan Mendoyo". Sulasmi, (2018) tentang "Pengaruh Model Pembelajaran POGIL Berbantuan Media Permainan TTS Terhadap Hasil Belajar IPA siswa Kelas V SD Gugus IV Cempaka Putih Kecamatan Kubutambahan Kabupaten Buleleng tahun pelajaran 2017/2018". Hal ini dilihat dari hasil perhitungan uji-t diperoleh $t_{\text {hitung }}=5,103$ dan $t_{\text {tabel }}=2,012$ ( $\left.t_{\text {hitung }}>t_{\text {tabel }}\right)$. Adanya perbedaan terhadap hasil belajar IPA siswa menandakan bahwa model pembelajaran POGIL berbantuan media permainan TTS berpengaruh positif terhadap hasil belajar IPA siswa. Berdasarkan hasil analisis 
data menunjukan bahwa terdapat perbedaan yang signifikan hasil belajar IPA antara kelompok siswa yang dibelajarkan dengan model pembelajaran SAVI berbantuan media Mind Mapping dengan kelompok siswa yang dibelajarkan dengan model pembelajaran konvensional.

Berdasarkan pemaparan tersebut dapat dinyatakan bahwa model pembelajaran Process Oriented Guided Inquiry Learning berbantuan media Mind Mapping berpengaruhterhadap kompetensi pengetahuan IPA siswa kelas V SD Negeri Gugus Kapten Japa Tahun Ajaran 2019/2020".

\section{METODE PENELITIAN}

Jenis penelitian yang dilakukan adalah penelitian kuantitatif dengan desain eksperimental yaitu Quasi Eksperimen (Eksperimen Semu). Desain penelitian ini memiliki kelompok control, namun tidak bisa sepenuhnya mengontrol variabel- variabel luar yang mempengaruhi pelaksanaan eksperimen (Sugiyono, 2017:77). Hal ini dikarenakan kemampuan peneliti dalam mengamati perilaku siswa sangat terbatas terutama ketika siswa berada di luar sekolah, dalam penelitian ini juga tidak memiliki kemampuan untuk mengetahui persepsi siswa terhadap perlakuan secara pasti. Desain eksperimen yang digunakan adalah "Nonequivalent control group design".

Populasi merupakan kelompok yang jumlahnya lebih besar dan digunakan untuk mengeneralisasikan hasil penelitian (Setyosari, 2015:221). Sedangkan menurut Agung (2014:69) populasi merupakan keseluruhan objek dalam suatu penelitian. Populasi penelitian ini adalah seluruh siswa kelas V SD Negeri Gugus Kapten Japa Tahun Ajaran 2019/2020, yang terdiri dari 13 kelas dalam 6 sekolah dasar. Jumlah populasi dari penelitian ini adalah 456 siswa. Menurut (Agung, 2014:87), sampel merupakan salah satu bagian dari populasi yang diambil dengan teknik tertentu dan dianggap mewakili seluruh populasi. Teknik yang digunakan mengambil sampel dari populasi disebut dengan teknik cluster random sampling. Teknik ini dilakukan dengan cara menyampurkan subjek - subjek dari populasi sehingga semua subjek mendapatkan kesempatan yang sama kepada anggota populasi untuk diambil menjadi anggota sampel. Setelah dilakukan pengundian diperoleh 2 kelas sampel yaitu kelas VA SD No. 17 Dauh Puri yang memiliki jumlah siswa sebanyak 38 siswa dan kelas V SD No. 4 Dauh Puri. setelah dua kelas terpilih, maka dua sampel tersebut akan dilaksanakan uji kesetaraan untuk mengetahui tingkat kesetaraan kedua kelas yang akan digunakan sebagai kelas eksperimen dan kelas kontrol. Untuk mencari tahu tingkat kesetaraan maka peneliti memberikan pretest dala, penelitian. Adapun diuji prasyarat yang dilakukan terlebih dahulu yaitu uji normalitas sebaran data dengan teknik Kolmogorov-Smirnov dan uji homogenitas varians. Jika kedua kelompok sampel sudah setara maka dapat dilanjutkan dengan memberikan perlakuan. Metode pengumpulan data yang digunakan penelitian ini adalah metode tes dan instrumen yang digunakan dalam adalah tes pilihan ganda. Instrumen ini digunakan untuk mengukur kompetensi pengetahuan IPA siswa pada dua kelas yang diberikan perlakuan yang berbeda, yaitu kelas eksperimen dan kelas kontrol. Tes adalah alat atau prosedur yang dipergunakan unruk mengukuran dan menilaian, berupa pernyataan, perintah, petunjuk yang ditunjukan kepada siswa untuk mendapatkan respons sesuai dengan tujuan penelitian, dengan mengukur tingkat kemampuan siswa atau mengungkap aspek tertentu dari siswa yang akan diberikan tes (Daryanto,2016:71). Tes pilihan ganda biasa menyediakan alternative jawaban a, b, c dan d yang apabila siswa menjawab benar butir tes mendapat skor 1 dan skor 0 apabila siswa menjawab salah. Setelah melalui proses uji coba yaitu, uji validitas, uji daya beda, uji tingkat kesukaran dan uji reliabilitas maka diperoleh tes kompetensi pengetahuan IPA yang valid sebanyak 40 soal yang terdiri dari 21 soal cukup, 16 soal baik dan 3 soal sangat baik. Dari uji tingkat kesukaran diperoleh 3 soal mudah, 37 soal sedang dan 1 soal sukar dan soal kompetensi pengetahuan IPA reliabel.

Metode analisis data yaitu metode analisis statistik inferensial. Statistik inferensial data yang dianalisis adalah gains skor yang ternormalisasi dari hasil pre-test dan post-test data kemampuan IPA. Data gain skor yang diperoleh akan di uji menggunakan uji statistik parametrik yaitu dengan uji-t apabila telah memenuhi uji prasyarat analisis normalitas dan homogenitas.

\section{ANALISIS DAN PEMBAHASAN}

Berdasarkan permasalahan yang terjadi, Penelitian ini adalah eksperimen dengan memberikan perlakuan pada dua sampel yaitu kelas VA SD N 17 Dauh Puri menjadi kelas eksperimen dan kelas V SD N 04 Dauh Puri menjadi kelas kontrol. Pada kelas eksperimen diberikan perlakuan model pembelajaran POGIL berbantuan Mind Mapping sedangkan pada kelas kontrol diberikan perlakuan model pembelajaran konvensional. Setiap kelas diberikan perlakuan sebanyak 6 kali dan setelahnya diberikan posttest yang bertujuan untuk mendapatkan data nilai dari setiap sampelnya. 
Berdasarkan perhitungan yang dilakukan diperoleh nilai mean, standar deviasi dan varians dari data posttest kedua kelompok penelitian sebagi berikut.

Tabel 1. Deskripsi data Kompetensi Pengetahuan IPA

\begin{tabular}{lcc}
\hline \multicolumn{1}{c}{ Deskripsi Data } & Kelompok Eksperimen & Kelompok Kontrol \\
\hline $\mathrm{N}$ & 40 & 35 \\
Mean & 0.57 & 0.43 \\
Standar Deviasi & 0.083 & 0.060 \\
Varians & 0.007 & 0.004 \\
\hline
\end{tabular}

Data yang diperoleh dari penelitian ini kemudian dianalisis dengan beberapa tahapan yaitu uji normalitas, uji homogenitas dan uji hipotesis. Berdasarkan hasil analisis normalitas sebaran data dari data gain skor ternormalisasi sampel penelitian kelompok eksperimen, diperoleh nilai maksimum $\left|\mathrm{F}_{\mathrm{T}}-\mathrm{F}_{\mathrm{S}}\right|$ yaitu 0.097 kemudian nilai tersebut dibandingkan dengan nilai tabel Kolmogorov-Smirnov = 0,210. Hal ini menunjukkan bahwa nilai maksimum $\left|\mathrm{F}_{\mathrm{T}}-\mathrm{F}_{\mathrm{S}}\right|<$ nilai tabel Kolmogorov-Smirnov dapat diartikan data pada hasil kompetensi pengetahuan IPA kelompok eksperimen dikatakan berdistribusi normal.

Hasil analisis uji normalitas sebaran data dari gain skor ternormalisasi sampel penelitian kelas kontrol, diperoleh nilai maksimum $\left|\mathrm{F}_{\mathrm{T}}-\mathrm{F}_{\mathrm{S}}\right|$ yaitu 0.087 kemudian nilai tersebut dibandingkan dengan nilai tabel Kolmogorov-Smirnov $=0,224$. Hal ini menunjukkan bahwa nilai maksimum $\left|\mathrm{F}_{\mathrm{T}}-\mathrm{F}_{\mathrm{S}}\right|$ nilai tabel Kolmogorov-Smirnov dapat diartikan data hasil Kompetensi Pengetahuan IPA kelompok kontrol berdistribusi normal.

Uji homogenitas varians ini dilaksanakan berdasarkan data kompetensi pengetahuan IPA yang menggunakan data gain skor kelompok eksperimen dan kelompok kontrol. Uji homogenitas dilaksanakan agar mengetahui mengenai adanya perbedaan yang dapat terjadi dalam uji hipotesis memang benar bisa terjadi diakibatkan karena ada beda varians diantara kelompok, bukan sebagai akibat perbedaan dalam kelompok. Uji homogenitas varians dalam penelitian ini mempergunakan uji F. Varians terbesar yaitu 0.007 dibagi varians terkecil 0.004 sehingga mendapatkan hasil 1.5. Dari hasil analisis, diperoleh $\mathrm{F}_{\text {hitung }}=$ 1.5 , hasil ini kemudian dibandingkan dengan harga $F_{\text {tabel }}$ pada derajat kebebasan $(\mathrm{dk})$ untuk pembilang $\mathrm{n} 1-1(40-1=32)$ dan derajat kebebasan $(\mathrm{dk})$ untuk penyebut n2-1 $(35-1=30)$ diperoleh $\mathrm{F}_{\text {tabel }}=1.76$. Hal ini berarti $F_{\text {hitung }}=1.75<\mathrm{F}_{\text {tabel }}=1.76$, sehingga data gain skor ternormalisasi kompetensi pengetahuan IPA antara kelas eksperimen dan kelas kontrol memiliki variansi yang homogen.

Hipotesis diuji adalah $\mathrm{H}_{0}$ yaitu tidak ada perbedaan signifikan Tidak terdapat perbedaan yang signifikan Kompetensi Pengetahuan IPA antara kelompok yang dibelajarkan dengan model pembelajaran POGIL berbantuan Mind Mapping dengan kelompok yang dibelajarkan melalui pembelajaran konvensional pada kelas V SDN Gugus Kapten Japa Tahun Ajaran 2019/2020. Uji Hipotesis menggunakan uji-t dengan rumus polled varians. Rumus uji t dengan rumus polled varians. Dengan kriteria apabila $t_{\text {hitung }} \leq t_{\text {tabel, }}$, artinya $\mathrm{H}_{\mathrm{o}}$ diterima dan $\mathrm{H}_{\mathrm{a}}$ ditolak, dan apabila $\mathrm{t}_{\text {hitung }}>\mathrm{t}_{\text {tabel }}$ artinya $\mathrm{H}_{\mathrm{o}}$ ditolak dan $\mathrm{H}_{\mathrm{a}}$ diterima.

Pada taraf signifikan $5 \%$ dengan $\mathrm{dk}=\mathrm{n}_{1}+\mathrm{n}_{2}-2$. Rekapitulasi hasil analisis uji t data posttest sebagai berikut.

Tabel 2. Hasil Analisis Uji-t Data Post-test

\begin{tabular}{clcccc}
\hline No. & Kelompok Sampel & $\mathbf{N}$ & $\mathbf{D k}$ & $\mathbf{t}_{\text {hitung }}$ & $\mathbf{t}_{\text {tabel }}$ \\
\hline 1 & Eksperimen & 40 & 73 & 8.08 & 1.99 \\
2 & Kontrol & 35 & & \\
\hline
\end{tabular}

Berdasarkan hasil uji hipotesis dari kompetensi pengetahuan IPA kelompok eksperimen dan kelompok kontrol diperoleh $\mathrm{t}_{\text {hitung }}=8.08$ dalam taraf signifikansi $5 \%$ dengan $\mathrm{dk}=\mathrm{n} 1+\mathrm{n} 2-2=(40+35-$ 2) $=73$ menunjukkan nilai $t_{\text {tabel }}=1,99$ sehingga $t_{\text {hitung }}>t_{\text {tabel }}$ yaitu $t_{\text {hitung }}=8.08>t_{\text {tabel }}=1,99$. Maka $H_{o}$ ditolak. Hal ini berarti terdapat perbedaan yang signifikan kompetensi pengetahuan IPA kelompok siswa yang dibelajarkan dengan model pembelajaran POGIL berbantuan Mind Mapping dengan kelompok siswa yang dibelajarkan melalui pembelajaran konvensional pada kelas kelas V SDN Gugus Kapten Japa. Model pembelajaran POGIL berbantuan Mind Mapping dapat membuat siswa menjadi lebih aktif dan berpikir kritis serta dapat membuat pengetahuan yang telah didapat oleh siswa menjadi lebih terstruktur. Pada kelompok kontrol diterapkannya pembelajaran yang dilakukan oleh guru wali kelas yang dimana lebih berpusat pada penyajian informasi sehingga terlihat peran guru sangat dominan. Adapun tahapan pada model pembelajaran POGIL berbantuan Mind Mapping antara lain : 1) Orientasi; 2) Eksplorasi; 3) Pembentukan Konsep, 4) Aplikasi, 5) Penutup. Hasil penelitian ini juga diperkuat oleh Mahayana, I Made 
Helly (2016) tentang "Pengaruh Model Pembelajaran POGIL Dan Minat Belajar Terhadap Pemahaman Konsep IPA Siswa Kelas IV SDN 1 SD di Gugus VI Kecamatan Sukasada". terdapat pengaruh yang signifikan pemahaman konsep IPA antara kelompok siswa yang dibelajarkan dengan model pembelajaran POGIL dan kelompok siswa yang dibelajarkan dengan pembelajaran konvensional (Sig. $=0,001$ ). Marcelia, dkk (2016) ,dalam hasil penelitiannya berkesimpulan adanya hasil yang menunjukkan perbedaan yang signifikan antara siswa yang mendapatkan perlakuan menggunakan pembelajaran konvensional dengan siswa yang mendapat perlakuan dengan menggunakan model pembelajaran POGIL Dan Minat Belajar Terhadap Keterampilan Proses Sains Pada kelas V SD. Penelitian memperoleh data $t_{\text {hitung }}$ sebesar 10,224 > $t_{\text {tabel }}$ sebesar 4,00. Pawitra, Pt. Marta (2013) tentang "Pengaruh Model Pembelajaran SFAE Berbantuan Media Mind Mapping Terhadap Penguasaan Konsep IPA Siswa Kelas IV SDN 1 Sangsit Tahun Ajaran 2012/2013". Hasil perhitungan dengan uji-t, diperoleh thit adalah 4,562. Sedangkan ttab dengan taraf signifikansi $5 \%$ dan $d b=75$ adalah 2,000 . Hal ini berarti, thit lebih besar dari $t_{\text {tabel }}\left(t_{\text {hitung }}>t_{\text {tabel }}\right)$, sehingga hasilnya signifikan. Dengan demikian dapat disimpulkan bahwa terdapat perbedaan yang signifikan penguasaan konsep IPA antara siswa yang mengikuti pembelajaran dengan model pembelajaran SFAE berbantuan media Mind Mapping dan siswa yang mengikuti pembelajaran dengan model pembelajaran konvensional pada kelas IV Semester II Tahun Pelajaran 2012/2013 di SDN 1 Sangsit.

Berdasarkan pemaparan tersebut, maka dapat disimpulan bahwa terdapat pengaruh model pembelajaran POGIL berbantuan media Mind Mapping terhadap kompetensi pengetahuan IPA siswa kelas V SD Negeri Gugus Kapten Japa Tahun Ajaran 2019/2020.

\section{KESIMPULAN}

Sesuai dengan hasil analisis data post-test menunjukkan bahwa nilai rata-rata kelompok eksperimen dan kelompok kontrol $(0.57>0.43)$. Dari analisis uji hipostesis dengan uji-t diperoleh $t_{\text {hitung }}$ $=8.08$. Sedangkan pada taraf signifikansi $5 \%$ dan $\mathrm{dk}=(40+35-2)=73$ maka diperoleh nilai $\mathrm{t}_{\text {tabel }}=1,99$. Karena $t_{\text {hitung }}>t_{\text {tabel }}$ yaitu $t_{\text {hitung }}=8.08>t_{\text {tabel }}=1,99$ ini berarti $H_{o}$ ditolak. Hal ini membuktikan bahwa terdapat perbedaan yang signifikan kompetensi pengetahuan IPA siswa yang dibelajarkan melalui model pembelajaran POGIL berbantuan media Mind Mapping dengan kelompok siswa yang dibelajarkan melalui pembelajaran konvensional. Jadi diperoleh kesimpulan bahwa terdapat pengaruh model pembelajaran POGIL berbantuan media Mind Mapping terhadap kompetensi pengetahuan IPA siswa kelas V SD Negeri Gugus Kapten Japa Tahun Ajaran 2019/2020 .

Sesuai temuan penelitian yang diperoleh, untuk guru, kepala sekolah serta peneliti lainnya supaya siswa dapat mengikuti model pembelajaran POGIL berbantuan media Mind Mapping dengan lebih aktif agar siswa mampu memperoleh pengalaman belajar yang lebih bermakna, memberikan masukan bagi kepala sekolah agar dapat dijadikan pedoman bagi sekolah dan pendukung sumber belajar bagi guru sehingga dapat menciptakan kualitas pembelajaran di sekolah dasar, serta agar dijadikan referensi untuk melaksanakan penelitian selanjutnya atau menemukan inovasi kegiatan pembelajaran yang bermakna bagi siswa.

\section{DAFTAR PUSTAKA}

Arifin, Muhammad, and Prodi. 2018. "Pengaruh Media Pembelajaran Mind Mapping Terhadap Hasil Belajar Kognitif Dan Psikomotorik IPA Siswa Kelas IV SD Negeri 01 Kandangmas." JGK (Jurnal Guru Kita). https://doi.org/10.1017/CBO9781107415324.004

Agung, A. A. Gede. (2014). Metodologi Penelitian Pendidikan. Aditya Media Publishing

Buzan. (2015). Buku Pintar Mind Maping . Jakarta: PT Gramedia Pustaka Utama

Cahyono, Tri. (2015). Statistik Uji Normalitas. Purwokerto: Yayasan Snitarian Banyumas

Dewi. (2018). Pengaruh Model Pembelajaran Think Talk Write Berbantuan Mind Mapping Terhadap kompetensi pengetahuan IPA Kelas IV SD Gugus Kompyang Sujana Denpasar Utara Tahun Ajaran 2017/2018. Journal for Leasson and Learning Studies, 1(2).https://ejournal.undiksha.ac.id/index.php/JJPGSD /article/view/14720.

Dewi, Ni Putu Melistyana, I Ketut Ardana, and I Gusti Agung Oka Negara. 2017. "Pengaruh Model Pembelajaran Inkuiri Berbantuan Media Konkret Terhadap Kompetensi Pengetahuan IPA Siswa 
Kelas V SD Negeri Gugus Yos Sudarso Denpasar Selatan Tahun Pelajaran 2016/2017." E-Journal PGSD Universitas Pendidikan Ganesha

Dwi Handayani, Ni Made, Ni Nyoman Ganing, and Ni Wayan Suniasih. 2017. "Model Pembelajaran Picture And Picture Berbantuan Media Audio-Visual Terhadap Kompetensi Pengetahuan IPA." Journal of Education Technology. https://doi.org/10.23887/jet.v1i3.12502

Dionisius, dkk. (2019). Pengaruh Model Pembelajaran POGIL terhadap Keterampilan Proses Sains Siswa kelas V SD di Gugus VI Kecamatan Sukasada Tahun Pelajaran 2017/2018. MIMBAR PGSD Undiksha, 7(3). https://ejournal.undiksha.ac.id/index.php/JJPGSD/article/view/19464.

Hanson, David M. (2006). Instruction's Guided to Process Oriented Guided Inquiry Learning. Pacific Crest. https://POGIL.org/uploads/media_items/POGIL-instructor-sguide1.orogonal.pdf

Hunnicutt, Sally S., Alexander Grushow, and Robert Whitnell. 2015. "Guided-Inquiry Experiments for Physical Chemistry: The POGIL-PCL Model." Journal of Chemical Education. https://doi.org/10.1021/ed5003916

I Gst. Pt. Ragendra Wiratman, Ni Kt. Suarni, I Dw. Pt. Raka Rasana. 2013. "Pengaruh Model Pembelajaran Guide Inquiry Dan Model Pembelajaran Pogil Terhadap Kemampuan Menyelesaikan Soal Cerita Matematika Siswa Kelas V SD Di Desa Yehembang." Mimbar PGSD Universitas Pendidikan Ganesha

Juniantari, I Gusti Ayu Sri, and Ni Nyoman Kusmariyatni. 2019. "Pengaruh Model Pembelajaran Kooperatif Two Stay Two Stray Berbantuan Mind Mapping Terhadap Hasil Belajar IPA." Jurnal Ilmiah Sekolah Dasar. https://doi.org/10.23887/jisd.v3i3.19478

Kesuma, P. M. Hendra. (2017). Pengaruh Model Problem Based Learning Berbantuan Mind Mapping Terhadap Hasil Belajar IPA Siswa Kelas V SD di Gugus Peliatan Kecamatan Ubud Tahun Pelajaran 2016 / 2017. MIMBAR PGSD Undiksha, 5 (2). https: // e-journal. undiksha.ac.id /index.php /JJPGSD /article /view /10770.

Kosasih.(2014). Strategi Belajar dan Pembelajaran. Bandung: Yema Widya

Lestari, D. P. S. (2016). Pengaruh Model POGIL Dan Minat Belajar Terhadap Hasil Belajar IPA Pada Siswa Kelas V SD di Gugus I Kecamatan Gianyar Kabupaten Gianyar tahun pelajaran 2015/2016. MIMBAR PGSD Undiksha, 4 (1). https://ejournal.undiksha.ac.id/index.php/JJPGSD/article/view/7011.

Lestari, dkk .(2016). Pengaruh model pembelajaran Inkuiri Terbimbing Berbantuan Mind Mapping Terhadap Pemahaman Konsep IPA Siswa kelas IV di SD Gugus VI Kecamatan Sukasada tahun pelajaran 2016/2017. MIMBAR PGSD 5(3).https://ejournal.undiksha.ac.id/index.php/JJPGSD/ article/view/125421/7790.

Lestari, N. W. E. W. (2017). Pengaruh Model Pembelajaran Kooperatif Tipe Student Teams Achievement Divisions Berbantuan Mind Mapping Terhadap Kompetensi Pengetahuan IPA Siswa Kelas V SD Gugus Kompyang Sujana Denpasar Utara Tahun Ajaran 2016/2017. MIMBAR PGSD Undiksha, 5(2).https://ejournal.undiksha.ac.id/index.php/JJPGSD/article/view/10621

Mahayana, I. M. H. (2016). Pengaruh Model Pembelajaran POGIL Dan Minat Belajar Terhadap Pemahaman Konsep IPA Siswa Kelas IV SDN 1 SD di Gugus VI Kecamatan Sukasada. MIMBAR PGSD Undiksha, 4 (1) .https://ejournal.undiksha.ac.id/index.php/JJPGSD/article/view/6976

Malik, A., Oktaviani, V., Handayani, W., \& Chusni, M. M. (2017). Penerapan Model Process Oriented Guided Inquiry Learning (POGIL) untuk Meningkatkan Keterampilan Berpikir Kritis Peserta Didik. Jurnal Penelitian \& Pengembangan Pendidikan Fisika, 3(2), 127-136. https://doi.org/10.21009/1.03202 
Marcelia, dkk. (2016). Pengaruh Model POGIL Dan Minat Belajar Terhadap Keterampilan Proses Sains Pada kelas V SD di Gugus I Kecamatan Jembrana. MIMBAR PGSD Undiksha, 4 (1). https://ejournal.undiksha.ac.id/index.php/JJPGSD/article/view/6959/4749

Nanda Aprilia, Ghati. 2019. "Pengaruh Model Pembelajaran POGIL Terhadap Hasil Belajar IPA Pada Siswa Kelas IV Sekolah Dasar.” Jurnal Penelitian Pendidikan Guru Sekolah Dasar

Nureva, and Aulia Gustina Citra. 2017. "Pengaruh Penggunaan Model Pembelajaran Inkuiri Berbantuan Mind Mapping Dan Picture Mapping Terhadap Hasil Belajar IPA Pada Siswa Kelas V Sekolah Dasar." Terampil Jurnal Pendidikan Dan Pembelajaran Dasar

Pawitra, Pt. M. (2013). Pengaruh Model Pembelajaran SFAE Berbantuan Media Mind Mapping Terhadap Penguasaan Konsep IPA Siswa Kelas IV SDN 1 Sangsit Tahun Ajaran 2012/2013. MIMBAR PGSD Undiksha. 5 (2). https://ejournal.undiksha.ac.id/index.php/JJPGSD/article/view/10770.

Setyosari. (2015). Metode Penelitian Pendidikan dan Pengembangan. Jakarta: Prenada Media Group

Simonson, Susan E. S. (2013). Implementing POGIL in Undergraduate Biomechanics: Lessons Learned by A Novice. Journal of STEM Education, 14 (56-63).

Sri Yani Widyaningsih, Haryono, Sulistyo Saputro. 2013. "Model MFI Dan POGIL Ditinjau Dari Aktivitas Belajar Dan Kreativitas Siswa Terhadap Prestasi Belajar." Inkuiri

Subarkah, Cucu Zenab, and Ade Winayah. 2015. "Pengembangan Keterampilan Berpikir Kritis Siswa Melalui Process Oriented Guided Inquiry Learning (POGIL).” Jurnal Pengajaran Matematika Dan Ilmu Pengetahuan Alam. https://doi.org/10.18269/jpmipa.v20i1.562

Sugiyono. (2013). Model Penelitian Pendidikan (Pendekatan Kuantitatif, Kualitatif dan R\&D). Bandung: Alfabeta

Sugiyono. (2017). Metode Penelitian Kuantitatif, Kualitatif dan R\&D. Bandung: Alfabeta

Sulasmi, Ni Made Tini. 2018. "Pengaruh Model Pembelajaran Pogil Berbantuan Media Permainan TTS Terhadap Hasil Belajar IPA Siswa Kelas V SD.” Journal for Lesson and Learning Studies. https://doi.org/10.23887/jlls.v1i2.14718

Susanto, Ahmad. 2014. Teori Belajar dan Pembelajaran di Sekolah Dasar .Cetakan Ke-2.Jakarta: Prenada media Group

Rismawati, Ni W. Rawa, and Ni Nyoman Ganing. 2019. “Pengaruh Model Pembelajaran Mind Mapping Berbantuan Media Audiovisual Terhadap Kompetensi Pengetahuan IPA." Journal for Lesson and Learning Studies. https://doi.org/10.23887/jlls.v2i3.19509

Rustam, Agus Ramdani, and Prapti Sedijani. 2017. "Pengaruh Model Pembelajaran Process Oriented Guided Inquiry Learning (POGIL) Terhadap Pemahaman Konsep IPA, Keterampilan Proses Sains Dan Kemampuan Berpikir Kritis Siswa." Jurnal Penelitian Pendidikan IPA. https://doi.org/10.29303/jppipa.v3i2.90

Trianto. 2012. Model - model Pembelajaran Inovatif Berorientasi Konstruktivistik. Jakarta: Prestasi Pustaka.

Yudiari, dkk. (2015).Pengaruh Model Pembelajaran SAVI Berbantuan Media Mind Mapping Terhadap Hasil Belajar IPA Siswa Kelas V SD di gugus II Kecamatan Mendoyo. MIMBAR PGSD Undiksha, 3 (1). https://ejournal.undiksha.ac.id/index.php/JJPGSD/article/view/5683/4137

Wayan, I, Pradnya Setiawan, I Kadek Suartama, Dewi Arum, Widhiyanti Metra Putri, and Jurusan Pgsd. 2017. “Pengaruh Model Pembelajaran Learning Cycle 5E Berbantuan Mind Mapping Terhadap Hasil 
Widiantini, Ni Nyoman Ayu Sri, Made Putra, and I Wayan Wiarta. 2017. "Model Pembelajaran Sets (Science, Environment, Technology, Society) Berbantuan Virtual Lab Berpengaruh Terhadap Kompetensi Pengetahuan IPA." Journal of Education Technology. https://doi.org/10.23887/jet.v1i2.11776

Yuliani, N. P, dkk. (2017). Model Pembelajaran Process Oriented Guided Inquiry Learning Berbantuan Peta Pikiran Terhadap Hasil Belajar IPA Siswa Kelas V SD. MIMBAR PGSD Undiksha, 4 (2). https://ejournal. undiksha.ac.id/index.php/JET/article/view/11773

Yudiari, dkk. (2015). Pengaruh Model Pembelajaran SAVI Berbantuan Media Mind Mapping Terhadap Hasil Belajar IPA Siswa Kelas V SD di gugus II Kecamatan Mendoyo. MIMBAR PGSD Undiksha, 3(1). https://ejournal.undiksha.ac.id/index.php/JJPGSD/article/view/5683/4137 